Мария Шкаброва

\title{
ПРОПОЗИЦИОНАЛЬНЫЕ УСТАНОВКИ В КОНТЕКСТЕ СИТУАЦИИ ЗНАКОМСТВАВ
}

Аннотация. С решением концептуального замешательства в рамках контекстов пропозициональных установок связано появление и развитие семантической теории знакомства. Автор работы рассматривает различные контексты пропозициональных установок, такие как желание, вкус, убеждение, прибегая к обзору формальных трудностей, возникающих в их среде. Также предпринимается попытка объяснения проблем и неоднозначностей с помощью теории информации и анализа когнитивных процессов.

Ключевые слова: семантика, пропозициональные установки, контекстуализм, прагматика, теория информации.

\section{Maria Shkabrova}

\section{PROPOSITIONAL ATTITUDES IN THE CONTEXT OF ACQUAINTANCE SITUATIONS}

Abstract. The emergence and development of the semantic theory of aquaintaince is associated with the solution of conceptual confusion within the context of propositional attitudes. The author considers various contexts of propositional attitudes, such as desire, taste, belief, knowledge, resorting to the consideration of difficulties that arise in their environment. There is also attempting to explain problems and ambiguities using information theory and cognitive process analysis.

Keywords: semantic, propositional attitudes, contextualism, pragmatic, theory of information.

Для цитировАния: Шкаброва М. В. Пропозициональные установки в контексте ситуации знакомства // Логико-философские штудии. 2021. Т. 19, № 2. С. 156 160. DOI: 10.52119/LPHS.2021.98.74. 016.

Обратимся к примерам, которые приводит Куайн (Quine 1956). Фразу «Эрнест охотится на львов» можно проинтерпретировать двояко:

1. под «львами» подразумевается некоторое собирательное понятие;

\footnotetext{
${ }^{1}$ Шкаброва Мария Васильевна - студент, сотрудник проекта Российского общества истории и философии науки «Семантическая структура пропозициональных установок сознания».

Maria Shkabrova, undergraduate student, research fellow at the project of Russian Society for History and Philosophy of Science "The semantic structure of the propositional attitudes of consciousness". rojerdeep@gmail.com

${ }^{2}$ Работа выполнена в рамках проекта Русского общества истории и философии науки, поддержанного грантом РНФ № 21-18-00496 «Семантическая структура пропозициональных установок сознания».
} 
2. словом «лев» обозначен конкретный объект, уникальный в своем роде.

Мы видим, что в первом случае область действия квантора существования шире, потому как он предполагает возможность указания на множество, состоящее из более чем одного объекта. Эрнест в такой ситуации не имеет никакого определенного представления о льве, на которого он охотится, хотя мы и понимаем, что в результате поимки добыча окажется совершенно конкретной. В de re-контексте область действия квантора значительно сужается, поскольку субъект высказывания концентрируется на отдельной вещи. Куайн выражает описанную разницу определениями «понятийного смысла»и «относительного смысла».

Оба примера иллюстрируют особое интенциональное отношение между говорящим и предметом его речи. Такое отношение Куайн, вслед за Расселом, называет пропозициональной установкой. В примере с Эрнестом и львом пропозициональная установка появляется в контексте желания («Эрнест хочет, чтобы...»), но этим их область употребления не ограничивается. Наиболее широко распространенные контексты возникновения пропозициональных установок - чувство (именно как вкус, ощущение), убеждение (мнение, верование) и знание, а также их разновидности.

\section{а) Контекст желания}

Одним из самых распространенных источников неоднозначности являются языковые средства, выражающие отношение желания. Тем не менее, их активное употребление не мешает достижению коммуникативных целей. С другой стороны, многие теоретики затрудняются отразить формальную сторону использования подобных выражений.

Например, при употреблении оператора желания в некоторых случаях возникает проблема третьего прочтения, о которой писала Дж. Фодор. М. Швагер предоставляет широкую трактовку подобного вида выражений, именуя общий случай «buyers' intentions» (Schwager 2011: 8).

Здесь требуется дополнительно указать на значительное замечание: в предложениях разбираемого типа речь идет не об актуальных, существующих в действительном мире вещах. М. Швагер приводит множество сценариев, основательно завязанных на темпоральности как на одном из своих аспектов. Вещь обладает или не обладает бытием независимо от момента произношения высказывания, поэтому, когда говорится: «Адриан хочет купить такой же жакет, как у Мальте», неважно, существует ли вещь в действительном мире во время произнесения этого высказывания. Поэтому, на мой взгляд, поставленную проблему нельзя решить, пренебрегая ее прагматической стороной. Об этом писал Э. Соса, вводя отличительный терм и говоря о том, что его содержание становится ясным только из контекста (Sosa 1970: 891-892). 
Мария Шкаброва. Пропозициональные установки в контексте ситуации знакомства

M. Швагер также предлагает ввести отношение когнитивного контакта (Schwager 2011: 11). Это отражает необходимость в восполнении формальной картины пропозициональной установки желания, однако мы не находим объекта в его актуально-физическом воплощении. Тем не менее, интенция создает отношение чисто когнитивного характера, поэтому можно взять в качестве объекта некоторый цельный образ, который находится в возможности воплощения и не обязательно в действительности. Это также эффективный выход для формализации высказываний, содержащих оператор желания и имеющих объект только, например, в будущем.

\section{б) Контекст суждений вкуса}

Этот вид высказываний характеризуется употреблением таких предикатов, как 'вкусно/невкусно', 'приятно/неприятно' и остальных, связанных с чувственными восприятиями, в том числе запаха, осязания, зрения, слуха. По сути, когда мы говорим: «Этот перец — красный» или «Здесь пахнет рыбой» - мы находимся вне пропозициональной установки, поскольку характеризуем объект, а не наше к нему отношение.

Несмотря на то что суждения вкуса всегда прямо отсылают к конкретному ощущению, в нашей обыденной практике мы постоянно употребляем высказывания, содержащие предикаты вкуса, в случае, когда мы не имеем непосредственного опыта знакомства с вещью.

Исходя из этого, Нинан выдвигает предположение (в рамках одного аналитического подхода) о необходимости пресуппозиции (Ninan 2014: 295). Иными словами, мы не можем определить истинностное значение высказывания, если мы не имеем опыта восприятия объектов в качестве пресуппозиции. Однако данное утверждение оказывается проблематичным для некоторого рода высказываний. Поэтому Нинан прибегает к иному способу анализа - эпистемическому подходу. Важно, что эпистемический подход имеет прагматическое значение. Согласно Нинану, такой подход способен вывести нас из затруднений, которые не смог разрешить пресуппозициональный подход. Это объяснимо, поскольку, в том числе, эпистемический подход учитывает контекстуальные параметры.

\section{в) Контекст убеждения}

Здесь мне бы хотелось обратиться к теории информации, которую описывает Дрецке (Dretske 1981). Подробнее о самой информации сказано в другом месте, сейчас моей целью является подчеркнуть ее роль в формировании установки убеждения, а также связь с процессами восприятия.

У нас есть два способа описания восприятия вообе:

1. экстенсиональный, например: «Он смотрит на утку»; 
2. интенсиональный: «Он видит, что это утка».

Во втором случае мы конкретно имеем в виду: он распознает нечто, как утку, в отличие от первого, где он может, допустим, видеть утку, летящую в небе, но думатъ, что это гусь. Иными словами, предложение (1) не содержит никаких намеков на содержание представления, имеющегося у человека, видящего утку.

Дрецке пишет: внутреннее состояние, которое является необходимым условием ви́дения утки (то есть такое, без которого мы не видим утку, хотя можем смотреть на нее), есть отправная точка в процессе выработки чувственной (sensory) информации. В таком состоянии информация об утке кодируется в аналоговую форму, обеспечивающую подготовку для ее избирательного преобразования когнитивными центрами (где продуцируется в том числе убеждение в том, что это утка). Под аналоговой формой, я думаю, здесь понимается образ, возникший в результате представления. Обобщая:

1 этап (input): мы нечто видим = то, информацию о чем мы получаем;

2 этап (output): мы нечто увидели (распознали) = то, что мы получаем в результате успешно прошедших когнитивных процессов.

Такую роль играет опыт в формировании устойчивых убеждений. Однако в рамках данной теории предполагается стабильный мир, хотя бы некоторая часть событий или вещей которого могут быть сочтены устойчивыми. В этом прослеживается прагматический элемент, определяющий, что именно является достаточно устойчивым, способным составить среду условий перемещения потока информации. Дрецке называет это, дословно, «условия канальности» (channel conditions) область, ограниченная фиксированными, стабильными и устойчивыми условиями, внутри которых рассчитывается поток информации.

Предполагается, что убежденность - это некоторое внутреннее состояние, содержание которого выразимо как «s есть $F »$, причем имеется в виду: это сказано, опираясь на информацию о том, что «s есть $F \gg$. Сигнал, передающий информацию, должен обладать такими физическими характеристиками (быть достаточно выразительными, сильно влиять на субъекта), чтобы стать причиной убеждения (состояния убежденности). Однако информация не сводится к простому знанию физической причины. Скорее она является опосредующим звеном между причиной и убежденностью.

Когда речь идет об установке убежденности, мы абстрагируемся от конкретных элементов чувственных представлений, при этом отдельные части информации все еще содержатся в сенсорном опыте объекта. Чтобы прояснить это, вспомним случай так называемого «двойного знакомства».

Куайн в своей работе «Quantifiers and Propositional attitudes» (Quine 1956) описал следующую ситуацию, к которой мы уже отсылали выше в измененном варианте. Ральф видит, как недалеко от него передвигается человек в черном плаще и шляпе. Обозначим его как Н. Ральф судит мужчину по внешнему виду и решает, 
что тот шпион. Как пишет И. Б. Микиртумов, для того чтобы прийти к такому выводу, Ральфу необходимо сперва какое-то время удерживать в сознании цельный образ Н для того, чтобы идентифицировать его как шпиона (Микиртумов 2018: 316).

Дрецке объясняет это первичное обобщение частных признаков до единого устойчивого образа тем, что контекст пестрит переизбытком информации, большинство которой не релевантно ситуации. В результате когнитивного процесса цифровизации (digitalization) из насыщенной информационной матрицы избираются наиболее существенные единицы информации и включаются в представление, то есть в свою аналоговую форму. Только благодаря данному процессу могут быть возможны дальнейшие распознавание, классификация и идентификация.

Итак, содержание убеждения характеризуется истинностным значением постольку, поскольку оно основано на информации. Являясь внутренней репрезентацией, убеждение может содержать в себе упущение некоторых обстоятельств дел. Это наталкивает на вывод о том, что устойчивость убеждения зависит от богатства его информационного содержания. Дрецке вполне поддерживает данную точку зрения, поскольку он называет знанием убеждение, подкрепленное достаточным количеством информации.

\section{Литература}

Микиртумов 2018 - Микиртумов И. Б. Семиотические факты // Логико-философские штудии. 2018. Т. 16, № 4. С. 311-334.

Ninan 2014 - Ninan D. Taste predicates and the acquaintance inference // Proceedings of SALT 24. 2014. P. 290-309.

Dretske 1981 - Dretske F. Knowledge and the Flow of Information. MIT Press, 1981.

Quine 1956 - Quine W. Quantifiers and propositional attitudes // Journal of Philosophy. 1956. Vol. 53, no. 5. P. 177-187.

Schwager 2011 - Schwager M. Speaking of Qualities // Proceedings of SALT 19. 2011. P. 395-412.

Sosa 1970 - Sosa E. Propositional Attitudes De Dicto and De Re // Journal of Philosophy. 1970. Vol. 67, no. 21. P. 883-896. 